\title{
LA REACTUALIZACIÓN DEL CUENTO MARAVILLOSO EN LA LITERATURA INFANTIL Y JUVENIL DE ROSA MONTERO
}

\author{
Eva María VILLAR SECANELLA \\ Universidad de Zaragoza \\ evillar@unizar.es
}

\section{Resumen}

En este artículo se analizan las estrechas relaciones que mantiene la trilogía de Rosa Montero: Las barbaridades de Bárbara, El viaje fantástico de Bárbara y Bárbara contra el Doctor Colmillos con el cuento maravilloso tradicional y las estrategias de reactualización que lleva a cabo la escritora en la búsqueda de complicidad entre el discurso narrativo y un lector en formación. Se incluye una breve propuesta didáctica para jóvenes lectores aprovechando aspectos relacionados con el potencial que nos ofrece el cuento y con el principal objetivo de desarrollar el hábito lector y la competencia literaria.

Palabras clave: cuento maravilloso, competencia literaria, hábito lector, lector en formación, didáctica.

\section{LA RÉACTUALISATION DU CONTE MERVEILLEUX DANS LA LITTÉRATURE POUR ENFANTS ET POUR LA JEUNESSE DE ROSA MONTERO}

\section{Résumé}

Cet article analyse les relations étroites entre la trilogie de Rosa Montero: Las barbaridades de Bárbara, El viaje fantástico de Bárbara y Bárbara contra el Doctor Colmillos ${ }^{1}$ avec le conte merveilleux traditionnel et les stratégies de réactualisation que l'écrivain met en œuvre à la recherche d'une complicité entre le discours narratif et un lecteur en formation. Une brève proposition didactique

\footnotetext{
1 Propuesta de traducción: Les barbaries de Barbara, Le voyage fantastique de Barbara et Barbara contre le Docteur Colmillos.
} 
pour les jeunes lecteurs est inclusive, en tirant parti des aspects liés au potentiel offert par le conte et avec l'objectif principal de développer l'habitude de lecture et la compétence littéraire.

Mots-clés: conte merveilleux, compétence litteraire, habitude de lecture, lecteur en formation, didactique.

\section{THE UPDATING OF FANTASY TALE IN ROSA MONTERO'S CHILDREN AND JUVENILE LITERATURE}

\section{Abstract}

This article explores the links between Rosa Montero's trilogy Las barbaridades de Bárbara, El viaje fantástico de Bárbara y Bárbara contra el Doctor Colmillos ${ }^{2}$ and the traditional fantasy tale. It analyses the way in which Montero updates traditional strategies in her search for complicity between the narrative discourse and a reader in development. The article also includes a brief didactic proposal exploring the tale's potentiality aimed at encouraging reading habits and literary competency in young readers.

Key words: tale, fantasy, literary competency, reading habit, reader in development, didactics

Rosa Montero es una escritora que habitualmente se dirige a un público adulto, pero en ciertas ocasiones focaliza su atención en un destinatario juvenil, como es el caso de la trilogía: Las barbaridades de Bárbara (1 ${ }^{\mathrm{a}}$ ed. 1996), El viaje fantástico de Bárbara (1ª ed. 1997) y Bárbara contra el Doctor Colmillos ( $1^{\mathrm{a}} \mathrm{ed}$. 1998). Sobre esta trilogía ya aparecen investigaciones con respecto a la experiencia onírica que supone su lectura (Villar, 2018) y en este artículo nos centramos en las estrategias que la escritora utiliza como modo de reactualizar el cuento maravilloso dentro de la literatura infantil y juvenil contemporánea.

La primera pregunta que nos hacemos es ¿cuáles son las características del cuento maravilloso tradicional y cuáles son las semejanzas que mantiene esta trilogía con estas características? Para responder a esta pregunta analizamos, principalmente, la segunda obra de esta trilogía El viaje fantástico de Bárbara por ser la más fiel a las características del cuento maravilloso tradicional, aunque toda la trilogía muestre rasgos comunes más o menos explícitos.

2 Propuesta de traducción: Barbara's Barbarities, Barbara's Fantastic Journey and Barbara against Doctor Colmillos. 


\section{Características del cuento maravilloso tradicional y semejanzas en la obra de Rosa}

\section{Montero.}

Siguiendo investigaciones de Vladimir Propp podemos observar diferentes características comunes en el cuento maravilloso tradicional; en este artículo destacamos tres de ellas, las relacionadas con su estructura, escenarios y actantes. En referencia a la estructura, este tipo de cuentos «comienza con una disminución o un daño causado a alguien [...], o bien con el deseo de poseer algo [...] y se desarrolla a través de la partida del protagonista del hogar paterno...» (Propp, 1974, p. 17). Es decir, se trata del comienzo de un viaje, el alejamiento de lo familiar hacia un lugar desconocido donde el héroe experimentará una serie de aventuras y participará en una serie de combates para, finalmente, regresar al hogar. Campbell, vinculando el cuento maravilloso a nuestros primeros ritos iniciáticos de pubertad, condensa la estructura en tres fases: «separación-iniciación-retorno» (Campbell 1984, p. 35).

En referencia a los escenarios y siguiendo las investigaciones de Vladimir Propp (1974), este nos informa de que el héroe habitualmente, en el cuento maravilloso tradicional, se encamina hacia el escenario de un bosque, un bosque denso, oscuro y misterioso que suele retener al héroe y aprisionarlo y que puede ser habitado por seres extraordinarios, así como pueden acontecer situaciones insólitas. Como ya hemos advertido, el cuento maravilloso tradicional se encuentra vinculado a nuestros primeros ritos iniciáticos de pubertad y este escenario típico también guarda relaciones con estos ritos: Al neófito se le separaba de lo familiar y se le adentraba en un bosque o, al menos, en una espesura, siempre fuera de la civilización. Durante el rito de iniciación el niño moría como niño y resucitaba como un hombre adulto, retornando a la tribu como miembro activo de la misma. Esa muerte podía ser simbólicamente representada por el engullimiento del niño por animales fabulosos que tras un tiempo lo escupían a la luz, o ser simbólicamente cocido, cortado en pedazos y resucitarlo, así como también podían existir torturas físicas, amputaciones o roturas de dientes... ¿Pero por qué en un bosque o una espesura? Por un lado, porque este espacio permitía celebrar el rito en secreto y ocultaba el misterio que le era transferido al neófito durante el tiempo que habitaba este lugar. Al neófito le eran transmitidos los conocimientos de la tribu, que se consideraban sagrados: métodos de caza, secretos de carácter religioso, conocimientos históricos, normas y mandamientos de las costumbres sociales... todo aquello que se consideraba necesario para la vida adulta. Y por otro lado, íntimamente relacionado con lo anterior, porque el bosque se percibía como la entrada al reino de los muertos, tan necesaria para 
la muerte del niño y resurrección del adulto; se debía atravesar el bosque para llegar al otro mundo.

Con respecto a los actantes y volviendo a Vladimir Propp (1987) aparecerán varios actantes que tendrán diferentes esferas de acción: el agresor, que es quien combate contra el héroe; el auxiliar, que socorre al héroe en su aventura; el donante, que le transfiere al héroe un objeto mágico; y el mismo héroe, que es quien parte, quien se aleja de escenarios familiares para efectuar la búsqueda.

Analizando El viaje fantástico de Bárbara con respecto a su estructura, comprobamos que efectivamente, cumple ciertas características comunes al cuento maravilloso tradicional. La heroína, Bárbara, se aleja de lo conocido y viaja a El Otro Lado por una disminución, una pérdida, la de su perro Canela, que ha desaparecido y según Margarita, una anciana vagabunda amiga de la heroína, se ha ido a El Otro Lado, un lugar que parece encontrarse en otra dimensión paralela a la nuestra; hasta allí viaja la heroína con sus amigos Tulipa y Borán y después de atravesar multitud de aventuras en ese mundo extraordinario, encuentran a Canela y regresan de nuevo, todos juntos, al hogar.

En la trilogía que nos ocupa, el bosque no es un espacio especialmente protagónico, aunque sí se observan, especialmente en El viaje fantástico de Bárbara, el simbolismo que este espacio representa en el cuento maravilloso tradicional. Por una parte se encuentra el hecho de que Bárbara, Tulipa y Borán viajen a El Otro Lado, otro mundo... Como Margarita les explica a los niños: «Además de este mundo en el que vivimos hay otro mundo diferente, un lugar que está muy cerca de nosotros pero al mismo tiempo muy lejos, porque ignoramos que existe» (Montero, 2007 a, p. 13). No se especifica que este Otro Lado sea el reino de los muertos, pero desde luego no pertenece al mundo conocido de los vivos: se compone por diferentes países en los que existen seres extraordinarios, acontecen situaciones insólitas y se percibe un subrayado animismo. Atraviesan espacios naturales: campos, desiertos o ríos cargados de misterio y peligros y, de hecho, Bárbara y sus amigos, en el Otro Lado, llevan como guía a El libro de la Selva, capaz de hablar y ofrecerles cierto sentido sobre el mundo que recorren. En ocasiones tropiezan con lugares que podríamos definir como civilizados y sin embargo son civilizaciones desconocidas para los vivos que habitamos este mundo.

Por otra parte, nos encontramos con la fuerte presencia de las muertes simbólicas, especialmente cuando Bárbara, Tulipa y Borán se encuentran en el País de los Agujeros, abriéndose un agujero enorme y negro «como la boca de una inmensa ballena» (Montero, 2007a, p. 28), nos dice el discurso narrativo, por el que caen «gritando y dando volteretas» (Montero, 2007a, p. 28). No pasa desapercibido el riesgo 
mortal de este hecho y sus marcadas asociaciones con el engullimiento del neófito por esos animales fabulosos de nuestros primeros ritos iniciáticos. O lo que acontece en el Cíber, ese río al que se arrojan Bárbara y sus amigos huyendo de monstruos y en el que las leyendas aseguran, según El Libro de la Selva, que «la gente desaparece a cachitos» (Montero, 2007a, p. 91). Y, efectivamente, esa parece ser la suerte que van a correr los tres niños cuando bolas de fuego, hoyos y robots rojos se enfrentan a los héroes perdiendo estos partes de su cuerpo, pies, hombros, codos... incluso Tulipa pierde la cabeza que Bárbara sostiene debajo de su brazo. Estas amputaciones, nuevamente, nos llevan a actos rituales propios de nuestros primeros ritos iniciáticos, situaciones de peligro mortal de las que el héroe deberá renacer.

En referencia a los actantes, los agresores se multiplican y varían a lo largo de la trilogía, aunque en la tercera obra se manifiesta como agresor protagónico el Doctor Colmillos, un dentista monstruoso y una analepsis que nos traslada a la primera obra de esta trilogía en la que Bárbara ya confiesa su temor por estos profesionales.

La auxiliar protagónica es Tulipa, la más íntima amiga de Bárbara, aunque los auxiliares también se multiplican y varían a lo largo de las tres obras.

Siguiendo investigaciones de Propp (1974), la forma clásica del donante es la maga. La maga se encuentra en el bosque y, más aún, ella misma es el espíritu del bosque y suele tener alguna conexión con el reino de los muertos. En la trilogía que nos ocupa, la donante principal es Margarita, que no vive en un bosque, sino en una ciudad contemporánea, ni tiene una conexión explícita con el reino de los muertos, pero sí con El Otro Lado y a menudo, como ella misma confiesa: «me voy al Otro Lado a darme una vuelta, visito a los amigos, hago turismo...» (Montero, 2007a, p. 15); y tampoco le transfiere exactamente objetos mágicos a Bárbara, la heroína, pero sí conocimientos secretos, como por ejemplo, el modo de acceso a El Otro Lado. Un modo de acceso similar a un acto ritual, en el que se subraya el humor absurdo dado que Bárbara y sus amigos, Tulipa y Borán, tendrán que presionar el botón de un semáforo mientras aguantan a la pata coja:

solo tenéis que levantar del suelo la pierna izquierda, eso es; dobladla para atrás, así, aguantad a la pata coja y, ahora, que alguno de vosotros apriete el botón del semáforo, ese que dice "Pulse peatón". ¿Estáis preparados? Porque, en cuanto lo apretéis, saldréis zumbando para el Otro Lado. (Montero, 2007a, p. 16) 
Y, por último, la heroína protagónica, como ya hemos indicado, Bárbara, aunque en ocasiones los papeles entre heroína y ayudantes puedan hibridarse y oscilar, principalmente, entre Bárbara, Tulipa y Borán, llegando incluso al concepto de héroe colectivo.

Como observamos, esta trilogía se encuentra marcada por una presencia protagónica de actantes femeninos y este aspecto, en realidad, no es algo ajeno al cuento maravilloso tradicional en el que no solo podemos encontrar una gran variedad de actantes femeninos donantes sino también agresoras, auxiliares e incluso heroínas.

\section{Divergencias entre el cuento maravilloso tradicional y la obra de Rosa Montero.}

Una vez analizadas las características del cuento maravilloso tradicional y las semejanzas que mantiene esta trilogía con las mismas, responderemos a una segunda pregunta: y entonces, ¿cuáles son las diferencias que se han llevado a cabo en la reactualización de este cuento maravilloso contemporáneo que nos ocupa?

La reactualización que esta trilogía lleva a cabo se encuentra marcada por una destacable búsqueda de complicidad con el joven lector contemporáneo.

En primer lugar, nos encontraríamos con los espacios, como ya hemos observado, relacionados simbólicamente con el misterio, lo extraordinario, el peligro y la muerte que se combinan, y aquí reside la novedad, con otros escenarios de carácter más realista y contemporáneo, propios de una ciudad occidental actual y con los que el joven lector podrá identificarse de manera directa.

Una segunda estrategia se encuentra en el distanciamiento humorístico de esta obra contemporánea. La constante voluntad de esta trilogía por generar la risa en su receptor supone no solo un distanciamiento humorístico capaz de desdramatizar las situaciones de riesgo que experimentan los personajes, y con ellos de alguna manera el lector, sino también una manera lúdica de transgredir normas y arquetipos tanto sociales como literarios a través de la risa tabú -acepción de Rodari-, generando la complicidad con el lector. Como Consuelo Armijo reflexiona «En el mundo del nonsense las ideas establecidas (lo tenido por natural) se tambalean, y en cierto modo se cuestionan.» (Armijo, 1988, p. 30)

Por otro lado, María Victoria Sotomayor clasifica el tratamiento humorístico como humor de situación y humor verbal (Sotomayor, 2006, pp. 66-69), siendo múltiples los ejemplos que podemos encontrar en esta trilogía a este respecto. 
En referencia al humor de situación encontramos varios episodios en esta trilogía, como por ejemplo, el ya mencionado y absurdo ritual con el que Bárbara y sus amigos acceden a El Otro Lado: a la pata coja y presionando el botón de un semáforo.

En lo relativo al humor verbal, aparecen expresiones idiomáticas y comparaciones sorprendentes que inducen a la risa tabú dentro de un lenguaje coloquial y actual: «Yo sé que el Marciano es guapo y a menudo alardeo de tener un hermano guapo, pero a él siempre le digo que es más feo que un piojo con diarrea (ahí es cuando él me retuerce el brazo)» (Montero, 2008, p. 86). Dentro del humor verbal, también podemos encontrar el juego sonoro de la palabra, como cuando en la tercera obra de esta trilogía Bárbara contra el Doctor Colmillos, se pronuncia un conjuro para defenderse del caos, «Margarita nos hizo aprender la palabra mágica del conjuro: Estubidubichubidariguay» (Montero, 2007 b, p. 60). Un conjuro benefactor que junto al carácter lúdico del juego sonoro de la palabra protege y desdramatiza de la amenaza mortal del caos.

En tercer lugar encontramos la voz narradora, el discurso narrativo abandona la voz en tercera persona típica del cuento maravilloso tradicional a favor de una voz autodiegética.

Bárbara es la protagonista de esta trilogía, una niña preadolescente de edad similar a la del previsible lector implícito, recurso propio de la LIJ con el que se facilita al lector la identificación con la heroína ficcional y también común al cuento maravilloso tradicional. Sin embargo, esta identificación y complicidad entre heroína y lector a partir de la edad compartida entre ambos, se encuentra subrayada por su carácter autobiográfico. La joven voz narradora autodiegética rememora su pasado: «Te voy a contar la historia más extraordinaria que puedas imaginar. Todo empezó cuando un día se perdió Canela» (Montero, 2007a, p. 7). Aunque se trate de un pasado que el discurso narrativo habitualmente puntualiza como inmediato: «El martes pasado, Tulipa y yo decidimos escaparnos de casa» (Montero, 2008, p. 9); «todo empezó hará cosa de un mes, cuando todavía hacía calor y era verano» (Montero, 2007b, p. 8).

La rememoración de una voz autodiegética, nos indica Rodríguez Fontela, le facilita al discurso narrativo la complicidad con su receptor:

La conciencia rememorativa del protagonista ayuda, creemos, a evocar nuestros propios recuerdos, a definir nuestra propia experiencia, a proyectar nuestros valores, a configurar, en fin, el esquema de nuestra propia conciencia que la obra sea capaz de configurar cuando interpretamos el sentido. (Rodríguez Fontela, 1996, p. 86) 
Por otro lado, la voz narradora en focalización sobre la protagonista es, coherentemente, de información limitada a su percepción momentánea y parcial por la observación directa, una voz alejada de la omnisciencia y, bajo este aspecto, una voz poco fiable, debilitándose su autoridad como guía del mundo ficcional que propone, distribuyendo el discurso narrativo jerarquías, obligando al lector a recomponer la historia, produciéndose descubrimientos unísonos entre este y la heroína, generándose a través de esta estrategia la intriga y la complicidad con el lector.

Estábamos impresionados y amedrentados. Entonces comenzamos a escuchar un chof, chof, chof. Nos miramos los tres a los pies y comprobamos que estábamos quietos. ¡Alguien o algo venía detrás de nosotros! El chof, chof, chof se oía cada vez más cercano. ¡Horror de horrores! Borán y yo nos abrazamos el uno al otro y Tulipa se puso delante de nosotros como para defendernos. ¡Qué estupenda es Tulipa!

Y cuando estábamos a punto de desmayarnos de puro miedo, entre las nieblas azulonas apareció una sombra y, luego, esa sombra se convirtió en un hombre mayor, como de la edad de mi padre, gordito, con bigote y con cara de susto. (Montero, 2007a, p. 81)

Por otro lado, el discurso narrativo, a través de esta joven voz autodiegética, presenta un discurso inmediato que oscila entre el monólogo narrativizado y el monólogo interior, dependiendo de la importancia que se le ofrezca a la acción o a los procesos psicológicos de la narradora-protagonista en cada momento de la obra. Sin duda la acción exterior de esta heroína se atiende de manera fundamental en las tres obras analizadas, del mismo modo que en el cuento maravilloso tradicional, aunque también, en esta reactualización del género, se atiende a su acción o aventura interior, es decir, su proceso de maduración. El grado de subjetividad del monólogo que aquí nos presenta Rosa Montero, no alcanza las cotas observadas en otras obras suyas como Bella y Oscura, siendo que la escritora utiliza una palabra que alterna tanto los desvíos hacia el significado como los caminos más directos, protegiendo al joven lector de la angustia que pudiera suponer una dilatada pérdida de sentido.

En este discurso inmediato próximo al monólogo interior donde «la voz y el verbalismo incontenible del protagonista se impone sobre la propia organización del material narrativo, dando la impresión de fragmentación» (Díaz Armas, 2006, p. 92), apreciamos un acercamiento a la improvisación, así como también podría vincularse al psicoanálisis que aconseja «decirlo todo, sin seleccionar, sin construir» (Ciplijauskaité, 1994, p. 212), requiriéndose de un lector activo en la lectura, generándose la ilusión de reproducción del lenguaje oral espontáneo y un discurso confesional más o menos introspectivo que subraya la necesidad de lector implícito, su voluntad de dirigirse a él, generar su complicidad a través de la técnica del escucha o interlocutor sobre la que reflexiona la investigadora Biruté Ciplijauskaité 
en su obra La novela femenina contemporánea (1970-1985) y en la que al joven lector se le incluye, en cierta medida y en algún grado, como parte integrante de la obra. La voluntad de esta técnica por suscitar complicidad en el lector, se intensifica de manera explícita en la trilogía que nos ocupa a través de apelaciones directas y continuas que el discurso narrativo le dirige, reforzándose el carácter confesional del discurso: «Te voy a confesar un secreto» (Montero, 2008, p. 96), subrayándose la presencia de Bárbara como narradora: «Como te cuento, el niño aquel volaba» (Montero, 2007a, p. 26), así como el papel de oyente-lector: «Como lo oyes: ¡detuvo a mi madre! Y yo a todo esto en casa de Tulipa sin enterarme» (Montero, 2008, p. 68). Esta estrategia metaficcional contribuye a generar la ilusión, ya no solo de un tiempo y espacio ficcional compartido entre narrador y lector, sino también ese tiempo y espacio real del que participan el contador de historias y sus oyentes en la literatura de transmisión oral.

En cuarto lugar observamos aspectos intertextuales relacionados con la novela épica e incluso extensibles a otras disciplinas artísticas y la transmedialidad.

La intertextualidad, reflexiona Antonio Mendoza, designa «la relación que los diferentes enunciados literarios tienen entre sí. Todo enunciado se relaciona con otros anteriores, lo que da lugar a las relaciones intertextuales o dialógicas» (Mendoza, 2004, p. 201). De este modo, los elementos intertextuales suponen un regreso al origen literario y artístico del que es heredero el texto, descubriendo las fuentes ficcionales de las que parte, activando la memoria del lector implícito al que se dirige, generando su complicidad a través de la memoria compartida y formándolo en la memoria colectiva a la que desea vincularlo.

Es en la segunda y tercera obra de esta trilogía: El viaje fantástico de Bárbara y Bárbara contra el Doctor Colmillos donde el discurso narrativo más se aproxima al género de la novela épica. Por otro lado, la novela épica guarda múltiples puntos en común con el cuento maravilloso tradicional: la importancia de la aventura exterior del héroe, una estructura próxima al monomito de Campbell o la habitual inclusión de elementos fantásticos. Como Teresa Colomer señala, la literatura infantil y juvenil más contemporánea busca nuevos escenarios, aproximándose a lo fantástico y misterioso, experimentando con «la anulación de fronteras entre realidad y fantasía en la obra de ficción». (Colomer, 2009, p. 203) Y es que esta oferta literaria actual denominada alta fantasía o fantasía épica juvenil, y que deriva de la novela épica, debe su auge en este nuevo siglo por «su relación con un 
fenómeno que se había ido desarrollando en paralelo: la ficción no escrita, como los juegos de rol y las pantallas del cine, la televisión y los videojuegos» (Colomer, 2009, p. 206). Este nuevo género suscita complicidad en el joven lector acercándose a la cultura popular en la que se encuentra socializado, siendo las tecnologías y los medios de comunicación los que desempeñan un papel esencial en sus vidas. Como señala la investigadora Roxana Morduchowicz, la cultura popular «es uno de los pocos espacios que, en la propia percepción de los jóvenes, les pertenece y participa activamente en la construcción de su identidad» (Morduchowicz, 2011, p. 71). Por otro lado, esta actual fantasía épica juvenil, produce series que requieren episodios protagonizados por los mismos personajes, como es el caso de Harry Potter o el de esta trilogía, obras de cierta longitud con fórmulas de lectura más o menos sencillas que permiten al lector sumergirse «en aventuras situadas en mundos donde se puede habitar de forma prolongada.» (Colomer, 2009, p. 217) y se permiten autorreferencias textuales que acompañan al lector durante un tiempo continuado, dilatando la ilusión de memoria compartida y generando una especie de complicidad.

En esta fantasía épica juvenil contemporánea a la que, de alguna manera, pertenece esta trilogía, aparecen diferentes disciplinas artísticas actuales de manera explícita como el cine: «A mí lo que me gusta es enamorarme de verdad, de los actores de cine, por ejemplo, como Johnny Deep, que estaba maravilloso en Eduardo Manostijeras» (Montero, 2008, p. 48); la publicidad: «Es como lo del anuncio ese del Zumosol pero de verdad» (Montero, 2008, p. 84); y muy especialmente los videojuegos. En el capítulo ocho, "Tulipa pierde la cabeza", de la segunda obra de esta trilogía El viaje fantástico de Bárbara, la heroína y sus amigos Tulipa y Borán, intentando escapar de diferentes monstruos que los persiguen, se lanzan al Cíber, el río que ya hemos mencionado con anterioridad, que supone el interior de un videojuego en el que los protagonistas son atacados por diferentes elementos y pierden diferentes partes de su cuerpo. Borán lo clarifica a través del significado directo de la palabra.

- Bueno, no sé si estamos de verdad dentro de un ordenador o no, pero esto es igual que un ordenador, funciona lo mismo. ¿No os dais cuenta? Las líneas de colores, las paredes y los suelos de cristal verde y las bolas rojas esas. Estamos dentro de algún juego, esas bolas rojas son el enemigo y nosotros tenemos que evitarlas. (Montero, 2007a, p. 93) 


\section{Propuesta didáctica}

Por último, y para finalizar, expongo una propuesta didáctica según directrices que ofrece Montserrat Grañeras (2004), aprovechando la riqueza intertextual de esta trilogía que es heredera, como hemos analizado a lo largo de este artículo, de características típicas del cuento maravilloso tradicional y en la que se incluyen ciertos recursos y variaciones que reactualizan el género acercándolo al lector joven de nuestra contemporaneidad.

Esta propuesta didáctica está destinada a alumnado a partir de $4^{\circ}$ de Educación Primaria y se divide en tres fases de aproximadamente 50 minutos cada una, teniendo por objetivo la formación integral de los jóvenes desde la literatura, el desarrollo de la competencia literaria de manera global, tanto lectura como escritura y la adquisición del hábito lector, acercándonos a la literatura desde el placer por la lectura. Para alcanzar estos objetivos nos centramos en dos de los capítulos de la segunda obra de esta trilogía El viaje fantástico de Bárbara: "No me gustan las arañas", en el que Bárbara, Tulipa y Borán habrán de combatir sus miedos personales y "Tulipa pierde la cabeza", en el que, como ya hemos mencionado, los tres amigos, esta vez, se lanzan al río Cíber, un espacio cibernético en el que deberán pasar por una serie de niveles en los que se enfrentan a diferentes peligros habitando un lugar similar al de los videojuegos.

Fase 1. Aprender a mirar un cuento maravilloso

Los objetivos de esta primera fase son: hacer consciente al alumnado, a través de la expresión oral, de la estructura primitiva del cuento maravilloso tradicional analizando el capítulo "No me gustan las arañas"; reflexionar sobre sus propios miedos; observar las características de personajes tanto femeninos como masculinos sin polemizar explícitamente sobre el tema, sino de manera implícita a través de la información que el discurso narrativo ofrece, así como capacitarlo para la realización de la fase 3 o tarea final que se propone: escribir un cuento próximo al discurso narrativo del videojuego.

Tras una lectura individual, se proponen una serie de preguntas en gran grupo con la finalidad de compartir la experiencia lectora del alumnado y guiar hacia los objetivos anteriormente indicados.

- ¿Cómo es el espacio que habitan los protagonistas? ¿Qué sensaciones transmite? ¿Por qué piensas que transmite esas sensaciones?

- ¿Quién crees que cumple el papel de héroe? ¿Qué te lleva a pensar esto?

- Intenta describir con un adjetivo a cada uno de los protagonistas. ¿Por qué has elegido ese 
adjetivo?

- ¿De qué objetos o características mágicas se valen los protagonistas?

- ¿Quién crees que cumple el papel de ayudante? ¿Qué te lleva a pensar esto?

- ¿Quién crees que cumple el papel de agresor? ¿Qué te lleva a pensar esto?

- ¿Reciben los héroes alguna recompensa? ¿Cuál crees que es?

- Si tú entraras en el País de los muchos miedos, ¿quién sería tu agresor y cómo lograrías vencerlo?

Fase 2. Empatizar con los agresores

Los dos objetivos principales de esta segunda fase es el de enfrentar al alumnado a sus propios miedos, así como el desarrollo de la empatía y creatividad a través de la expresión escrita.

Con esta finalidad se le pide al alumnado que elija o bien un agresor imaginario al que ellos teman, puede ser animado o inanimado, o bien uno de los agresores del capítulo "No me gustan las arañas", y redacte la biografía de este facilitándole un guión orientativo:

- ¿Cuál es su nombre y edad?

- ¿De dónde es?

- ¿Cómo es su familia?

- ¿Qué aficiones tiene?

- ¿Por qué razón se enfrenta al héroe?/ ¿Por qué razón se enfrenta a ti?

Fase 3. Tu propia aventura cibernética.

El objetivo de esta tercera fase o tarea final es el de consolidar la estructura primitiva del cuento tradicional, superar los propios miedos y fomentar la creatividad del alumnado a través de la expresión escrita y el trabajo cooperativo.

Con esta finalidad se propone la lectura individual del capítulo, "Tulipa pierde la cabeza", un discurso narrativo que mantiene la estructura primitiva del cuento maravilloso tradicional, aunque esta vez desde la reactualización que proporciona la transmedialidad de un discurso narrativo que se acerca al videojuego.

Tras la lectura individual de este capítulo el alumnado, en primer lugar, de manera individual, deberá reflexionar sobre el papel que cumplirá en su propia aventura cibernética a través de un guión orientativo: 
- Espacio que habita.

- Adjetivo que lo caracteriza.

- Objeto o característica mágica que posee.

- Agresor al que se enfrenta.

- Modo de resolución del conflicto.

En segundo lugar y en grupos preferentemente de tres, teniendo como modelo el capítulo "Tulipa pierde la cabeza", deberán producir un cuento escrito próximo al discurso narrativo del videojuego en el que el alumnado que compone el grupo pasará por tres niveles de dificultad o situaciones de peligro que deberá resolver en equipo y según las características que los representan y sobre las que han reflexionado previamente en la primera parte de la sesión. Entre ellos deberán pactar aspectos como las situaciones de peligro a las que deberán enfrentarse, agresores contra los que combatirán, modo de resolución de esos conflictos o recompensa final.

\section{Conclusión}

La trilogía de Rosa Montero analizada mantiene estrechas relaciones con el cuento maravilloso tradicional: estructura, escenarios simbólicamente relacionados con el misterio, el peligro y la muerte o los actantes que intervienen en el discurso narrativo.

El lector en formación podrá reconocer y sentirse cercano a este tipo de literatura primigenia a la que ha tenido acceso desde su primera infancia. Una complicidad que aumenta entre discurso y lector y que es explícitamente buscada por Rosa Montero reactualizando el cuento maravilloso tradicional en su obra al combinar escenarios fantásticos con espacios de carácter realista y contemporáneo; incorporando un humor que desdramatiza las situaciones de riesgo experimentadas, al mismo tiempo que transgrede normas; guiando a través de una voz narradora autodiegética, autobiográfica, de carácter confesional que requiere de la presencia de un oyente e incluyendo disciplinas artísticas actuales vinculadas, entre otras, con los videojuegos. Todas estas características facilitan que el discurso narrativo entable relaciones con el lector y lo convierten en una herramienta óptima para el desarrollo del hábito lector desde una lectura placentera, afectiva y significativa, así como al desarrollo de la competencia literaria y formación integral de los jóvenes. 


\section{Referencias bibliográficas}

Armijo, C. (1988). El nonsense, un arma contra las mentes cuadradas en Cuadernos de Literatura infantil y juvenil (CLIJ) $\mathrm{n}^{\circ} 45,28-31$.

Campbell, J. (1984). El héroe de las mil caras. Psicoanálisis del mito. México D.F: Fondo de Cultura Económica.

Ciplijauskaité, B. (1994). La novela femenina contemporánea (1970-1985) Hacia una tipología de la narración en primera persona. Barcelona: Editorial Anthropos.

Colomer, T.(2009). Entre la literatura y las pantallas: el auge de la fantasía épica en Teresa Colomer (coord.) en Lecturas adolescentes, (pp.197-219). Barcelona : Graó.

Díaz Armas, J. (2006). Personajes de la literatura juvenil: cambio y maduración, en María Victoria Sotomayor Sáez (coord.) Personajes y temáticas en la Literatura Juvenil. Aulas de verano, (pp.73-98). Madrid: Ministerio de Educación y Ciencia. Instituto Superior de Formación del Profesorado.

Grañeras Pastrana, M. (coord.). (2004). Investigación desde la práctica. Guía didáctica para el análisis de los videojuegos. $\mathrm{N}^{\mathrm{o}}$ 6. Madrid: Instituto de la Mujer.

Mendoza, A. (2004). La educación literaria, bases para la formación de la competencia lecto-literaria. Málaga: Ediciones Aljibe.

Montero, R. (1999). Bella y Oscura. Barcelona: Editorial Seix Barral, S.A.

_ (2007a). El viaje fantástico de Bárbara. Madrid: Alfaguara Infantil.

— (2007b). Bárbara contra el Doctor Colmillos. Madrid: Alfaguara Infantil.

— (2008). Las barbaridades de Bárbara. Madrid: Alfaguara Infantil.

Morduchowicz, R. (2010). La generación multimedia, en Gemma Lluch (coord.). Las lecturas de los jóvenes. Un nuevo lector para un nuevo siglo, (59-84). Barcelona: Editorial Anthropos.

Propp, V. (1974). Las raíces históricas del cuento. Madrid: Editorial Fundamentos.

— (1987). Morfología del cuento. Madrid: Editorial Fundamentos.

Rodríguez Fontela, M. Á. (1996). La novela de autoformación: una aproximación teórica e histórica al "Bildungsroman” desde la narrativa española. Kassel: Edición Reichenberger/Universidad de Oviedo. 
Sotomayor, M. V. (2006). Personajes de la literatura juvenil: cambio y maduración, en María Victoria Sotomayor Sáez (coord.) Personajes y temáticas en la Literatura Juvenil. Aulas de verano, (pp. 53-72). Madrid: Ministerio de Educación y Ciencia. Instituto Superior de Formación del Profesorado.

Villar Secanella, E. (2018). La experiencia onírica en la literatura infantil y juvenil de Rosa Montero, en Sueños de viaje - viajes soñados en la literatura infantil y juvenil. Christiane ConnanPintado y Elvira Luengo Gascón (dir.) Ondina/Ondine Revista de literatura comparada infantil y juvenil. Investigación en educación $\mathrm{n}^{\mathrm{o}}$ 2, 52-63. URL: https://papiro.unizar.es/ojs/index.php/ ond/issue/view/269. Última consulta: 20-10-2019. 